\title{
Anti-mullerian Hormone Serum Level as a Predictor of Responsiveness to Clomiphene Citrate Therapy in Iraqi Women with PCOS
}

\author{
Dhai Rashid (D), Raghda Bardan* (D) \\ Department of Obstetrics and Gynecology, College of Medicine, Al-Anbar University, Ramadi, Iraq
}

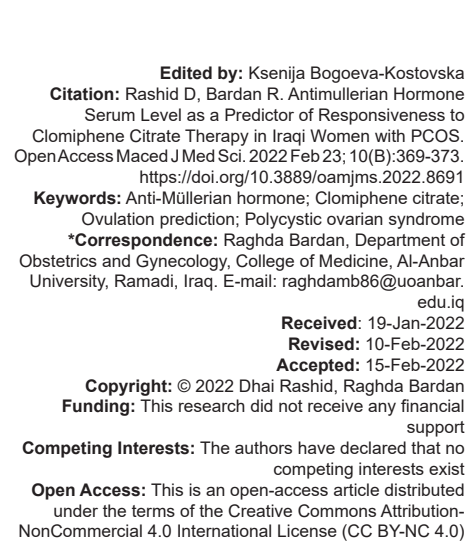

Introduction

Infertility is the second most common reason for women of childbearing age to attend their general practitioner. As nearly every seven heterosexual couples, there is one couple that has conceiving problems. For pregnancy to occur, there must be sperm and egg with the good fertile ability [1]. Common causes of infertility in the female are ovulatory and tubal factors [2]. Ovulatory disorders are a prominent cause of infertility, with polycystic ovary syndrome (PCOS) being the most prevalent. PCOS has a frequency of between $5 \%$ and $15 \%$ in the general population, depending on many variables such as phenotype, race, and the categorization system employed [3]. Due to the broad range of diagnostic criteria used, prevalence estimates range from $2.2 \%$ to as high as $26 \%$. When the Rotterdam criteria were used to diagnose PCOS, the prevalence was more than double what was seen when the National Institutes of Health criteria were employed. The prevalence of PCOS may be different according to ethnic background. For example, in comparison to
Caucasians, a higher prevalence is observed among females of South Asian origin, where the presentation of PCOS occurs at a younger age and has more severe symptoms [4]. The pathophysiology of PCOS seems to be due to multiple factors and polygenic [5]. There is controversy about the definition of this syndrome. Important features involve disturbances in the menstrual cycle, clinical or biochemical hyperandrogenism, and obesity [6]. There are many aspects other than ovarian aspects that contribute to the pathophysiology of PCOS, but ovarian dysfunction is central [7]. It has been recognized that females with $\mathrm{PCOS}$ have elevated serum levels of anti-mullerian hormone (AMH) [8]. $\mathrm{AMH}$ is one of the transforming growth factors- $\beta$ superfamily of peptides and its production is mainly by granulosa cells of the developing preantral and early antral follicles (AFC). Numerous studies have illustrated that $\mathrm{AMH}$ concentration is closely associated with AFC number [9]. Therefore, raised circulating $\mathrm{AMH}$ level in females with PCOS has strongly correlated to the large number of AFC related to this syndrome. The correlation between elevated blood AMH levels in females with PCOS and chronic infertility over a long period of time has been 
established, and seems to be connected to a variety of factors [10]. Initially, the activity of aromatase enzyme in human beings and mice granulosa cells is directly stopped by $\mathrm{AMH}$. In addition, Durlinger demonstrated that directly cultivating an in a vitro mouse model with $\mathrm{AMH}$ halted the formation of follicles from the resting primordial follicles pool and inhibited follicle-stimulating hormone (FSH)-stimulated preantral follicle growth. In the presence of $\mathrm{AMH}$, laboratory diagnostic studies on human granulosa cells show that the aromatase enzyme activity is inhibited and the follicular response to $\mathrm{FSH}$ is reduced [9]. Thus, increased $\mathrm{AMH}$ inhibits estradiol synthesis and the FSH action, interfering with the FSH/E2-induced feed-forward loop, which further increases the cellular FSH receptor count and allows follicles to grow and mature. In this manner, the idea that increased $\mathrm{AMH}$ is required for folliculogenesis may be developed [11]. There are many methods for PCOS patients to promote ovulation, which can ultimately result in a successful live delivery. Each of these therapies varies in terms of aggressiveness and efficacy. From lifestyle modifications to insulin sensitizing drugs, selective estrogen receptor modulators, aromatase enzyme inhibitors, and gonadotropins, to laparoscopic ovarian drilling and assisted reproductive methods, each method induces ovulation through a distinct mode of action. In many ovulatory women, the first-line therapy remains ovulation stimulation with antiestrogen medications [12]. Anti-estrogen therapy is effective in inducing ovulation in $73 \%$ of female patients, resulting in a $29 \%$ live birth rate [12]. Clomiphene citrate (CC) is a specific estrogen receptor modulator consisting of two isomers, zu-clompihene, and en-clompihene, with zu-clompihene being the more physiologically active by inhibiting estrogen receptors in the brain and pituitary, the anterior pituitary produces more gonadotropins, resulting in the ultimate maturation of follicles [3]. Using the best available knowledge to recognize women who are still unovulatory despite anti-estrogen treatment can guide these women to other therapeutic methods such as exogenous gonadotrophins, laparoscopic ovarian surgery, and insulin-sensitizing agents or more complicated assisted reproductive technology procedures, particularly in patients with increased reproductive age [13], [14]. In addition, the method of recognizing the elements that affect the prognosis also allows an insight into the abnormalities in the ovaries and the pathophysiology of anovulation [14]. Our study aimed to identify those females who will respond to treatment and the starting dose.

\section{Methods}

This study is an observational cohort study was conducted in Al-Ramadi and Al-Qaiem cities in outpatient clinics from January 2020 to February 2021 after informed consent for all participants. 79 women were included with a diagnosis of polycystic ovarian syndrome according to the Rotterdam criteria (two out of three) 1-Oligoovulation and/or anovulation (i.e., oligomenorrhoe or amenorrhoea) 2-hyperandrogenism (clinical features and/or biochemical elevation of testosterone) 3-Polycystic ovaries assessed by ultrasound. The inclusion criteria include patients. 1-Age 20-40 2-both primary and secondary infertility, with exclusion criteria include 1-Age more than 40. 2-Contraindications to CC 3-history of ovarian surgery 4-Thyroid disease. 5-Adrenal disease. 6-Significant Hyperprolactinemia. 7-Psychological disease or patient with a stressful life event. After complete history and examinations, all patients who meet the inclusion criteria were seen during the early follicular phase of the menstrual cycle (day 2 or 3 after spontaneous or progestogen promotion of menstrual bleeding) where ultrasound scanning was done to detect the volume of the ovaries (milliliters) and counting the AFC, blood samples were collected before the start of the first cycle of therapy with $\mathrm{CC}$ to establish the baseline blood level of $\mathrm{AMH}$. AMH was quantified using an AMH Gen II ELISA. The AMH II Gen ELISA is an enzymatically amplified two-site immunoassay. The measurement range (from a limit of detection to highest calibrator): 0.05 to approximately $22.5 \mathrm{ng} / \mathrm{ml}$. For the precision, the intra-assay coefficients of variation were $\leq 10.3 \%$ and the inter-assay coefficients of variation were $\leq 10.8 \%$. Measurements of the levels of other hormones involving luteinizing hormone, FSH), testosterone (T), insulin, and progesterone were also done. The participants receive $\mathrm{CC} 50 \mathrm{mg}$ for 5 days from the second to the $7^{\text {th }}$ day of the menstrual cycle. The patient's response to treatment is determined by transvaginal ultrasound monitoring of follicular growth till the appearance of a follicle of $18 \mathrm{~mm}$ and subsequent rupture of the follicle. Patients were considered as responders when there is a follicle of $18 \mathrm{~mm}$ regardless of the dose of $\mathrm{CC}$ used. If the ovulation does not occur, the dose of CC is increased to $100 \mathrm{mg}$ in the next menstrual cycle. The endpoint was when the first ovulation occurs and when the ovulation occurs, the dose remained unchanged in the subsequent cycles. All women in this research had at least three treatment cycles. Following ultrasound confirmation of ovulation, some patients received a progestational drug to support the luteal phase. Patients who ovulated during $\mathrm{CC}$ treatment, regardless of the dosage, were classified as responders. Three failed attempts to induce ovulation in three CC cycles despite maximal dosage stimulation $(100 \mathrm{mg} / \mathrm{d})$ were deemed CC-resistant anovulatory patient.

Table 1: The socio-demographic characteristics of the patients

\begin{tabular}{lllll}
\hline Variables & Min & Max & Mean & SD \\
\hline Age in Years & 17 & 40 & 25.72 & 4.97 \\
BMl kg/m & 18.49 & 37.11 & 27.28 & 4.48 \\
Infertility duration (years) & 1 & 13 & 3.43 & 2.78 \\
Dose & 50 & 150 & 112.03 & 29.10 \\
AMH level & 2.7 & 16.0 & 8.58 & 3.32 \\
\hline
\end{tabular}




\section{Statistical analysis}

The description-statistical analysis was performed using mean and standard deviation for numerical variables, frequent and percentage for categorical variables. The association between response status, age, body mass index (BMI), dose, and infertility duration was examined by the independent t-test. All analysis was performed using SPSS version 24 .

\section{Results}

Seventy-nine an ovulatory women with PCOS were involved in this study. They obtained 172 treatment cycles of CC.

Table 2: The responder and non-responder

\begin{tabular}{lll}
\hline Respond state & $\mathrm{n}$ & $\%$ \\
\hline Responder & 42 & 53.2 \\
Non-responder & 37 & 46.8 \\
\hline
\end{tabular}

Regarding the BMI was 27.28 so most of the women in this study were overweight.

The patients were grouped into two groups according to their response to CC.

Table 3: The association between Response status and age, $\mathrm{BMI}$, dose, and infertility duration

\begin{tabular}{|c|c|c|c|}
\hline \multirow[t]{2}{*}{ Variables } & No response & Response & \multirow[t]{2}{*}{$p$-value } \\
\hline & Mean \pm SD & Mean \pm SD & \\
\hline Age & $25.84 \pm 5.83$ & $25.62 \pm 4.14$ & 0.874 \\
\hline BMI & $26.21 \pm 4.38$ & $28.21 \pm 4.40$ & $0.04^{*}$ \\
\hline Dose & $108.33 \pm 24.48$ & $116.22 \pm 33.44$ & 0.657 \\
\hline Duration & $3.70 \pm 3.08$ & $3.20 \pm 2.50$ & 0.232 \\
\hline
\end{tabular}

There was a significant association of BMI between responder and non-responder with a $p$-value of 0.04 Of the 79 women included in a study of $6(7.6 \%)$ women ovulated at $50 \mathrm{mg}$ of CC. This increased to $42(92.9 \%)$. When the dose was increased to $100 \mathrm{mg}$ of CC, $37(46.8 \%)$ remained anovulatory (Figure 1 and Tables 1-3).

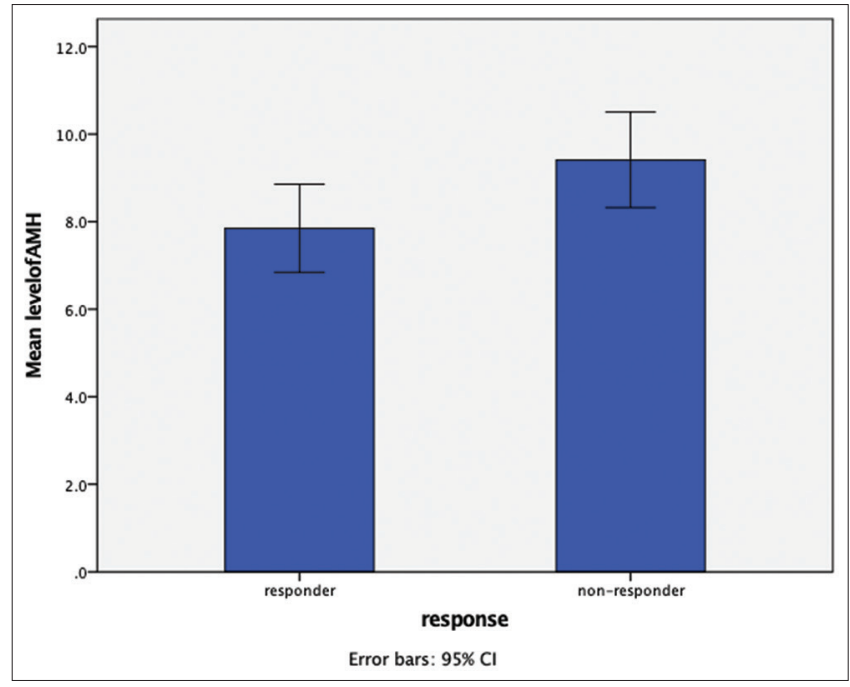

Figure 1: Mean anti-mullerian hormone level between responders and non-responders
Table 4: Mean AMH Level among responder and non-responder

\begin{tabular}{lll}
\hline Variable & Responder & Non-responder \\
\cline { 2 - 2 } & Mean \pm SD & Mean \pm SD \\
\hline AMH Level & $7.84 \pm 3.23$ & $9.41 \pm 3.27$ \\
\hline SD: Standerd deviation
\end{tabular}

The patient who ovulated had a significantly lower AMH level among responders $7.84+-3.23$ compared to non-responder $9.41+-3.27$ (Table 4).

The women who respond at $50 \mathrm{CC}$ had lower AMH $6.56+-2.2$ compared to women who responded at $100 \mathrm{CC}$ had $\mathrm{AMH}$ of $8.74+-3$ (Figure 2).

Table 5: Cut-off value sensitivity, specificity, accuracy, the positive predictive value (PPV), and the negative predictive value

\begin{tabular}{lclccccc}
\hline Variable & AUC & $\begin{array}{l}\text { Optimum cut } \\
\text { off value }\end{array}$ & Sensitivity & specificity & Accuracy & PPV & NPV \\
\hline AMH & 0.647 & 6.25 & $83.33 \%$ & $34.69 \%$ & $53.1 \%$ & $43.86 \%$ & $77.27 \%$ \\
\hline PPV: Positive predictive value, AMH: Anti-mullerian hormone. & & & &
\end{tabular}

The area under the curve (AUC) is 0.647 with an optimum cutoff value for $\mathrm{AMH}$ is 6.25 for responders from non-responders (Table 5).

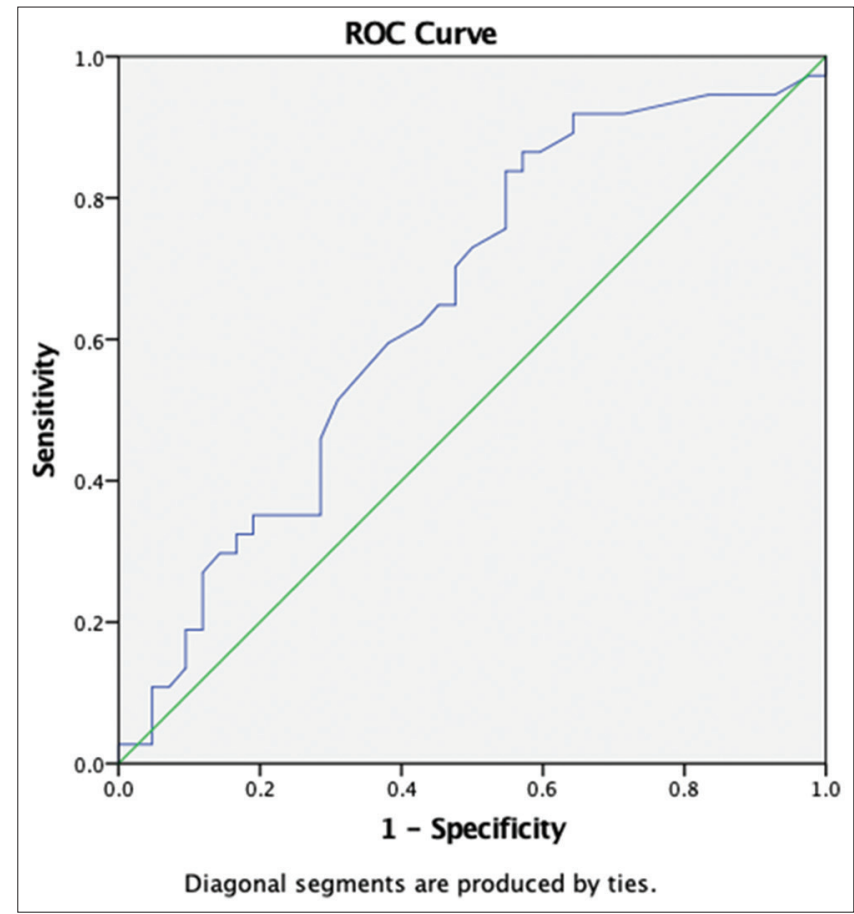

Figure 2: The optimum cut off value

\section{Discussion}

Although the serum AMH concentrations are known to be a reliable predictor of ovarian response in IVF, as high levels are regarded to anticipate an excessive ovarian response to gonadotropins treatment and decreased $\mathrm{AMH}$ level predicts diminished ovarian response to stimulation protocol [15]. In ovulation stimulation, oral medications such as oral CC produce 
a mild increase in serum FSH; however, this may not be enough to reduce intraovarain $\mathrm{AMH}$ to a range that is consistent with ovulation restoration [16]. As a result, patients with higher $\mathrm{AMH}$ concentrations are more severely inhibited and are less likely to react to oral cc. PCOS is a major cause of anovulation in females and there are subgroups of patients with PCOS who have elevated levels of $\mathrm{AMH}$ that impairs the effect of $\mathrm{FSH}$ and participate in the pathophysiology of PCOS in that group [6]. AMH increases in PCOS and is responsible for impaired folliculogenesis. These observations suggest that the higher the $\mathrm{AMH}$, the more impaired in disruption in folliculogenesis and less likely to respond to CC [17]. The study aims to identify this group of patients with high AMH levels. In addition, to find the specific cut of AMH beyond it, the response to $\mathrm{CC}$ is impaired in our Iraqi woman population as we supposed that this point is specific for each ethnic group. In this study, women who ovulated in response to $\mathrm{CC}$ had significantly lower $\mathrm{AMH}$ than women who did not ovulate in response to $C C$. compatible with the prior study of Maharan A and co-workers [18] which evaluates the effect of $\mathrm{AMH}$ on response rates of $\mathrm{CC}$ in sixty females with PCOS and found high circulatory $\mathrm{AMH}$ negatively correlated with the chance of ovulation and with the previous study of Wenyan who evaluates the effect of AMH level on the success of CC therapy in 81 anovulatory with PCOS and proves that with high $\mathrm{AMH}$ are more likely to not respond to cc treatment [19] and also with the study of Gülşen et al., who found that serum $\mathrm{AMH}$ level was seen to be useful in the prediction of CC resistance with a sensitivity of $66 \%$ and a specificity of $89 \%$ when the threshold for $\mathrm{AMH}$ concentration was $>12.38 \mathrm{ng} / \mathrm{ml}$ in PCOS patients [20]. The rate of response to CC in our study is $53 \%$. This is lower than the expected rate of ovulation for CC, which is written in most textbooks by $70-80 \%$. This can be illustrated by the reality that most of the women in the sample of our study were overweight. We have a cutoff point of 6.6 to predict no ovulation beyond this value with a sensitivity of $83 \%$ and specificity of $43 \%$ and a negative predictive value of $77.27 \%$. We compared the value of the cutoff of $\mathrm{AMH}$ in our study around the population of Iraqi women to the cut-off value in other studies. In our study, we found the level of $6.6 \mathrm{ng} / \mathrm{ml}$ and it is twice that of the previous study of Maharan et al. who reported a cut-off value of $3.4 \mathrm{ng} \backslash \mathrm{ml}$ [18] and it is approximate to the cutoff value reported by Wenyan found a cutoff value of 7.7 [19]. We suppose that the cut-off value differs from one community to another, which can be explained by the effect of genetic and environmental factors that influence the level of $\mathrm{AMH}$ and response to treatment. Further, different kits that are used for the measurement of $\mathrm{AMH}$ levels might result in considerable variation in serum $\mathrm{AMH}$, so each community may have a specific $\mathrm{AMH}$ of its own. The dose utilized had a maximum of $100 \mathrm{mg}$, as more than that $(150 \mathrm{mg})$ is not recommended by the US Food and
Drug Administration. In this investigation, we used no more than $100 \mathrm{mg}$ of CC.

\section{Conclusion}

The measurement of blood AMH levels in females with PCOS before therapy may be a useful tool for predicting the effect of CC treatment. This could be useful in counseling PCOS patients about the expected outcome of CC treatment, as well as making the ovulation induction protocol more customized and costeffective for the patient by starting ovulation induction for those with high levels of $\mathrm{AMH}$ with either high dose $\mathrm{CC}$ or chronic low dose gonadotrophins.

\section{References}

1. Keith D, editor. Nick raine $\square$ fenning. subfertility, reproductive problems. In: Edmonds, Christoph Lees and Tom Bourne. Dewhurst's Textbook of Obstetrics and Gynaecology. $9^{\text {th }}$ ed. London, UK: Wiley Blackwell; 2018: 691. Available from: https://www.goodreads.com/book/show/42190959-dewhursts-textbook-of-obstetrics-gynaecology [Last accessed on 2021 Dec 12].

2. Dun EC, Nezhat $\mathrm{CH}$. Tubal factor infertility: Diagnosis and management in the era of assisted reproductive technology. Obstet Gynecol Clin North Am. 2012;39(4):551-66. https://doi. org/10.1016/j.ogc.2012.09.006

PMid:23182560

3. Tanbo T, Mellembakken J, Bjercke S Ring E, Åbyholm T, Fedorcsak P. Ovulation induction in polycystic ovary syndrome. Acta Obstet Gynecol Scand. 2018;97(10):1162-7. https://doi. org/10.1111/aogs.13395

\section{PMid:29889977}

4. Wolf WM, Wattick RA, Kinkade ON, Olfert MD. Geographical prevalence of polycystic ovary syndrome as determined by region and race/ethnicity. Int $\mathrm{J}$ Environ Res Public Health. 2018;15(11):2589. https://doi.org/10.3390/ijerph15112589 PMid:30463276

5. Khan MJ, Ullah A, Basit S. Genetic basis of polycystic ovary syndrome (PCOS): Current perspectives. Appl Clin Genet. 2019;12:249-60. https://doi.org/10.2147/TACG.S200341 PMid:31920361

6. Rosenfield RL, Ehrmann DA. The pathogenesis of polycystic ovary syndrome (PCOS): The hypothesis of PCOS as functional ovarian hyperandrogenism revisited. Endocr Rev. 2016;37(5):467-520. https://doi.org/10.1210/er.2015-1104 PMid:27459230

7. Witchel SF, Oberfield SE, Peña AS. Polycystic ovary syndrome: Pathophysiology, presentation, and treatment with emphasis on adolescent girls. J Endocr Soc. 2019;3(8):1545-73. https://doi. org/10.1210/js.2019-00078

PMid:31384717

8. Dumont A, Robin G, Catteau-Jonard S, Dewailly D. Role of 
anti-Müllerian hormone in pathophysiology, diagnosis and treatment of polycystic ovary syndrome: A review. Reprod Biol Endocrinol. 2015;13:137. https://doi.org/10.1186/ s12958-015-0134-9

PMid:26691645

9. Almeida FR, Costermans NG, Soede NM, Bunschoten A, Keijer J, Kemp $\mathrm{B}$, et al. Presence of anti-Müllerian hormone (AMH) during follicular development in the porcine ovary. PLoS One. 2018;13(7):e0197894. https://doi.org/10.1371/journal.pone.0197894 PMid 30063719

10. Cook-Andersen $H$, Chuan SS, Maas K, Rosencrantz MA, Su HI, Lawson M, et al. Lack of Serum anti-Mullerian hormone responses after recombinant human chorionic gonadotropin stimulation in women with polycystic ovary syndrome. J Clin Endocrinol Metab. 2015;100(1):251-7. https://doi.org/10.1210/ jc. 2014-2948 PMid: 25303490

11. Mumford SL, Legro RS, Diamond MP, Coutifaris C, Steiner AZ, Schlaff WD, et al. Baseline AMH level associated with ovulation following ovulation induction in women with polycystic ovary syndrome. J Clin Endocrinol Metab. 2016;101(9):3288-96. https://doi.org/10.1210/jc.2016-1340

PMid:27228369

12. Perales-Puchalt A, Legro RS. Ovulation induction in women with polycystic ovary syndrome. Steroids. 2013;78(8):767-72. https://doi.org/10.1016/j.steroids.2013.05.005

PMid:23707553

13. Costello MF, Misso ML, Wong J, Hart R, Rombauts L, Melder A, et al. The treatment of infertility in polycystic ovary syndrome: A brief update. Aust N Z J Obstet Gynaecol. 2012;52(4):400-3. https://doi.org/10.1111/j.1479-828X.2012.01448.x PMid:22639834

14. Costello MF, Misso ML, Balen A, Boyle J, Devoto L, Garad RM, et al. Evidence summaries and recommendations from the international evidence-based guideline for the assessment and management of polycystic ovary syndrome: Assessment and treatment of infertility. Hum Reprod Open. 2019;2019(1):hoy021. https://doi.org/10.1093/hropen/hoy021

PMid:31486807

15. Choi MH, Yoo JH, Kim HO, Cha SH, Park CW, Yang KM, et al. Serum anti-Müllerian hormone levels as a predictor of the ovarian response and IVF outcomes. Clin Exp Reprod Med. 2011;38(3):153-8. https://doi.org/10.5653/cerm.2011.38.3.153 PMid:2238443

16. Dabkowska-Huć A, Lemm M, Sikora J, Witek A, Skałba P. Anti-Müllerian hormone dynamics during ovulation induction treatment with recombinant follicle-stimulating hormone in women with polycystic ovary syndrome. Endokrynol Pol. 2013;64(3):203-7. PMid:23873424

17. Dewailly D, Barbotin AL, Dumont A, Catteau-Jonard S, Robin G. Role of Anti-Müllerian hormone in the pathogenesis of polycystic ovary syndrome. Front Endocrinol (Lausanne). 2020;11:641. https://doi.org/10.3389/fendo.2020.00641

PMid:33013710

18. Mahran A, Abdelmeged A, El-Adawy AR, Eissa MK, Shaw RW, Amer SA. The predictive value of circulating anti-Müllerian hormone in women with polycystic ovarian syndrome receiving clomiphene citrate: A prospective observational study. J Clin Endocrinol Metab. 2013;98(10):4170-5. https://doi.org/10.1210/ jc.2013-2193

PMid:23979947

19. Xi W, Yang Y, Mao H, Zhao X, Liu M, Fu S. Circulating anti-Mullerian hormone as predictor of ovarian response to clomiphene citrate in women with polycystic ovary syndrome. J Ovarian Res. 2016;9:3. https://doi.org/10.1186/ s13048-016-0214-2

PMid:26864649

20. Gülşen MS, Ulu I, Köpük ŞY, Kıran G. The role of antiMüllerian hormone in predicting clomiphene citrate resistance in women with polycystic ovarian syndrome. Gynecol Endocrinol. 2019;35(1):86-9. https://doi.org/10.1080/095135 90.2018.1499085

PMid:30044165 